\title{
MEMBUDAYAKAN LITERASI PADA MASYARAKAT DI KELURAHAN GUNUNG BAHAGIA BALIKPAPAN SELATAN
}

\author{
Maryatin, Tutik Yuliani \\ ${ }^{1,2}$ Universitas Balikpapan \\ Email: maryatin@uniba-bpn.ac.id,
}

\begin{abstract}
Abstrack. Literacy culture in Indonesia is a very interesting issue to discuss. Given the literacy culture in Indonesia is still low and not ingrained in the community. In the midst of the rise of popular culture, books have never been a top priority. Even the people more easily absorb the culture of speaking and listening, rather than reading then pouring it in written form. Counseling and training in literacy cultivation is a reading activity for the community so they can think creatively and be able to follow changes such as the use of new innovations, the application of technology, and a mindset that is development-oriented. The result is reading or listening activities both from storytelling and watching videos.
\end{abstract}

Keywords : literacy, reading, writing

Abstrak. Budaya literasi di Indonesia menjadi persoalan yang sangat menarik untuk diperbincangkan. Mengingat budaya literasi di Indonesia masih rendah dan belum mendarah daging di kalangan masyarakat. Di tengah melesatnya budaya populer, buku tidak pernah lagi menjadi prioritas utama. Bahkan masyarakat lebih mudah menyerap budaya berbicara dan mendengar, dari pada membaca kemudian menuangkannya dalam bentuk tulisan. Penyuluhan dan pelatihan budidaya literasi ini merupakan kegiatan membaca untuk masyarakat sehingga dapat berpikir kreatif dan mampu mengikuti perubahan seperti penggunaan inovasi baru, penerapan teknologi, dan pola pikir yang berorientasi pada pembangunan. Hasilnya berupa kegiatan membaca ataupun menyimak baik dari mendongeng maupun menonton video.

Kata Kunci: literasi, membaca, menulis

\section{PENDAHULUAN}

Pembangunan yang sangat pesat dan perubahan yang terjadi di segala aspek kehidupan pada rakyat Indonesia membuat bangsa ini berlomba-lomba untuk meningkatkan kualitas dan kuantitas dirinya. Indikator-indikator pesatnya perkembangan yang terjadi ialah semakin besarnya aktivitas bangsa Indonesia. Perubahan yang terjadi di segala dimensi, baik di kota, maupun di daerah pedesaan sekalipun. Dengan diberlakukannya Undang-Undang No. 32 Tahun 2004 tentang Pemerintahan Daerah yang menandai lahirnya era otonomi daerah, maka masyarakat harus bersiap mandiri dan begerak aktif dalam mengembangkan daerahnya.

Kini, budaya literasi di Indonesia menjadi persoalan yang sangat menarik untuk diperbincangkan. Mengingat budaya literasi di Indonesia masih rendah dan belum mendarah daging di kalangan masyarakat. Di tengah melesatnya budaya populer, buku tidak pernah lagi menjadi prioritas utama. Bahkan masyarakat lebih mudah menyerap budaya berbicara dan mendengar, dari pada membaca kemudian menuangkannya dalam bentuk tulisan. Masyarakat Indonesia masih lebih banyak didominasi oleh budaya komunikasi lisan atau budaya tutur. Masyarakat cenderung lebih senang menonton dan mengikuti siaran televisi ketimbang membaca. Literasi sendiri secara sederhana diartikan sebagai kemampuan membaca dan menulis. Dalam konteks pemberdayaan masyarakat, literasi mempunyai arti kemampuan memperoleh informasi dan menggunakannya untuk mengembangkan ilmu pengetahuan yang bermanfaat bagi masyarakat. Budaya membaca dan menulis pada masyarakat Indonesia sampai menghadapi milenium baru ini sebenarnya masih sangat memprihatinkan.

Menurut Badan Penelitian dan Pengembangan Kemendikbud, kemampuan membaca anak usia 15 tahun hanya 37,6 persen anak membaca tanpa bisa menangkap makna. Dalam persoalan menulis, Indonesia hanya mampu menghasilkan 8.000 buku per tahun, tertinggal dari Vietnam yang mampu menghasilkan 15.000 buku per-tahun. Survei Unisco dilansir dari Laman, Republika, 26 Januari 2011. (Hadianto, 2001). Gambaran mengenai rendahnya minat baca ini juga tidak terlalu jauh berbeda dengan keadaan masyarakat dewasa ini. Indikator yang dapat dipergunakan 
adalah dengan melihat jumlah surat kabar yang dikonsumsi oleh masyarakat dewasa ini.

Beberapa hal yang menjadikan rendahnya budaya literasi di Indonesia antara lain, tingkat pendidikan masyarakat, malas membaca, minimnya akses dalam membaca. Ini disebabkan sedikitnya perpustakaan, harga buku yang cenderung tak terjangkau oleh daya beli masyarakat dan pemamfaatan teknologi yang tidak tepat, sehingga hanya sedikit yang mampu menuliskan pengetahuan yang diperoleh dari membaca atau menyimak.

Kelurahan Gunung Bahagia merupakan salah satu wilayah di kota Balikpapan. Secara geografis Gunung Bahagia berada di dataran tinggi, jumlah penduduk yang tercatat sebanyak 24.192 jiwa. Terkait dengan hal tersebut di atas, masih ditemukan beberapa masalah pada masyarakat Kelurahan Gunung Bahagia yang belum memiliki kemampuan membaca yang baik, tingkat minat baca di Kelurahan tersebut masih tergolong rendah, terdapat beberapa anak - anak putus sekolah maupun tidak putus sekolah yang belum bisa membaca, dan minimnya perhatian orang tua dalam menerapkan pendidikan literasi. Hal tersebut terbukti dengan survei pendahuluan yang peneliti lakukan sebelumnya.

Dengan adanya pendidikan dan pembiasaan kegiatan membaca kepada masyarakat, diharapkan masyarakat dapat berpikir kreatif dan mampu mengikuti perubahan seperti penggunaan inovasi baru, penerapan teknologi, dan pola pikir yang berorientasi pada pembangunan. Sebab masyarakat yang tidak mampu berubah untuk mengikuti perkembangan zaman akan semakin tertinggal. Oleh karena itu, kegiatan Pengabdian Masyarakat yang akan dilaksanakan selama 4 bulan ini mengangkat judul "Membudayakan Literasi pada Masyarakat di Kelurahan Gunung Bahagia Kecamatan Balikpapan Selatan Tahun 2018."

\section{METODE}

Kegiatan Pengabdian Masyarakat ini dilaksanakan dengan memberdayakan masyarakat setempat untuk berpartisipasi aktif. Metode budidaya literasi ini dilakukan melalui penyuluhan kepada masyarakat. Dengan Program Literasi meliputi empat tahap yaitu tahap persiapan, pelaksanaan, evaluasi dan penyusunan laporan pada bidang pendidikan. Berikut diuraikan mekanisme dari masing-masing tahap.

1. Persiapan

Pada tahap persiapan, hal-hal yang dilakukan antara lain: a. Analisis awal mengenai kondisi dan permasalahan

b. Melakukan koordinasi dengan LPPM Universitas Balikpapan

c. Mengindentifikasi masalah

d. Penyusunan proposal Pengabdian Masyarakat

e. Pembentukan kelompok belajar yang melibatkan masyarakat di Kelurahan Gunung Bahagia Balikpapan

f. Penyusunan jadwal dan tata tertib belajar kelompok

g. Pemberian motivasi untuk membaca (pentingnya pendidikan) sekaligus perkenalan dan menyampaikan nama kelompok, sistematika belajar kelompok serta tata tertib

Tahap persiapan ini disusun dengan tujuan memudahkan langkah dalam menggalakkan budidaya literasi pada masyarakat Kelurahan Gunung Bahagia. Terutama untuk menemukan masalah yang nantinya akan ditangani oleh pengabdi.

2. Pelaksanaan

a. Kegiatan literasi ini akan dilaksanakan dua kali dalam satu minggu di Kelurahan Gunung Bahagia Balikpapan. Setiap kelompok terdiri dari 20 orang, di mana akan dilakukan pendampingan. Saat kegiatan pendampingan membaca berlangsung, tim pengusul dan mahasiswa akan memantau proses pembelajaran. Adapun pembagian pendamping adalah sebagai berikut:

b. Masyarakat usia dewasa akan didampingi oleh dosen.

c. Masyarakat usia anak-anak akan didampingi oleh mahasiswa.

3. Evaluasi

Evaluasi dilaksanakan setiap dua minggu oleh pengusul. Evaluasi dilakukan dengan wawancara kepada pendamping, mahasiswa serta masyarakat. Hal ini dilakukan untuk mengetahui tingkat keberhasilan serta kendala dari kegiatan yang dilaksanakan. Selain itu, selama Program ini berlangsung akan diadakan evaluasi dengan kuesioner sebanyak dua kali yaitu pada pertengahan dan akhir pelaksanaan program.

4. Penyusunan Laporan

Penyusunan laporan meliputi laporan akhir dan artikel ilmiah. Penyusunan laporan dilaksanakan setelah semua kegiatan telah dilaksanakan dan dievaluasi.

Program pengabdian masyarakat ini merupakan langkah awal pengurus untuk 
membiasakan anak asuh belajar dalam kelompok. Setelah pengabdian ini selesai, kegiatan belajar kelompok masih tetap dapat berjalan dengan arahan dari pengurus.

\section{HASIL DAN PEMBAHASAN}

Kegiatan pengabdian membudidayakan literasi ini dilakukan pada masyarakat yang minat bacanya masih tergolong rendah di RT. 19 Kelurahan Gunung Bahagia, Balikpapan Selatan. Khususnya pada masyarakat usia dewasa maupun usia anak-anak baik yang putus sekolah maupun tidak.

Selama penyampaian materi, para peserta dapat mengikutinya dengan baik. Terbukti saat pemateri memaparkan tentang rendahnya minat
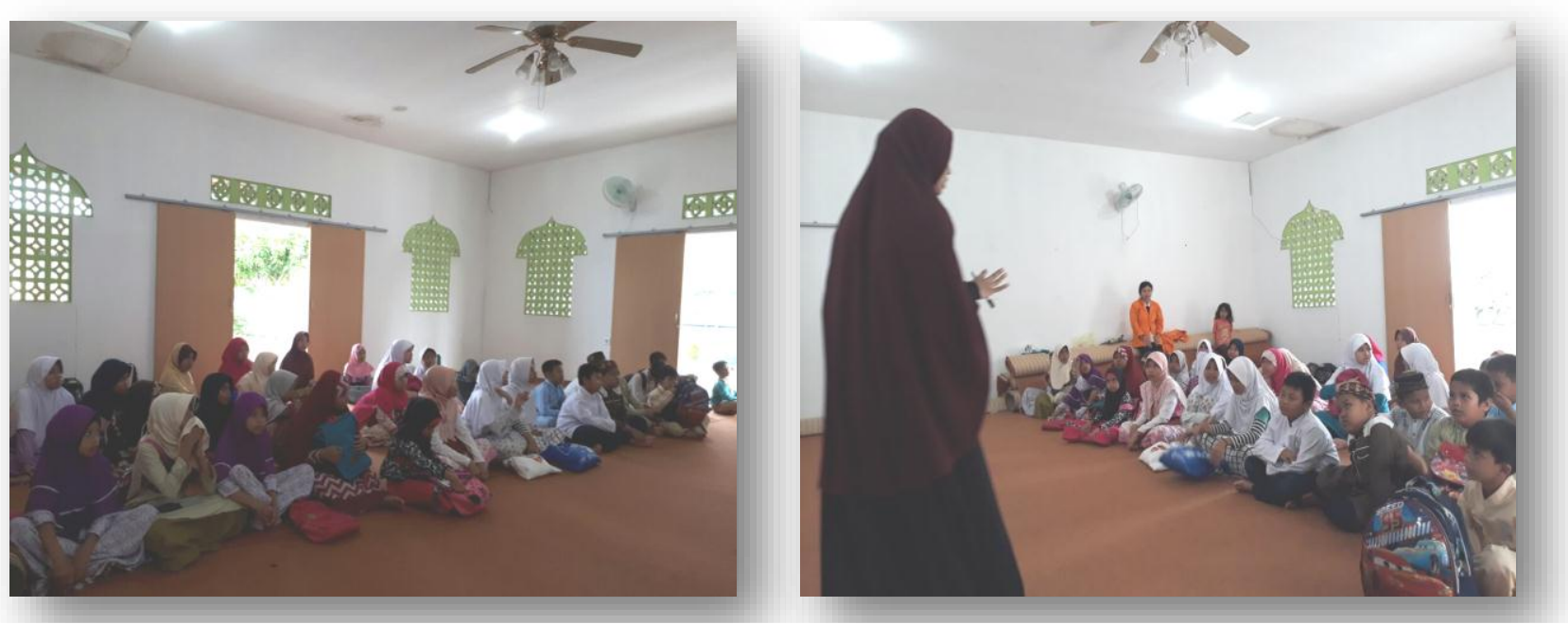

Gambar 1. Pemberian Materi Budidaya Literasi dan Pentingnya Membaca pada Para Peserta

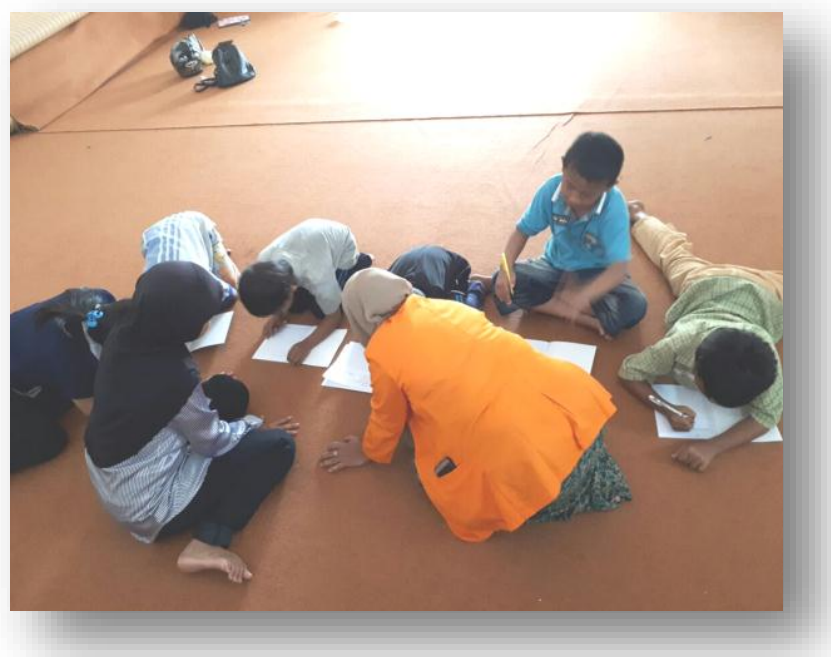

Gambar 2. Kegiatan Pendampingan Membaca Bergiliran pada Anak Putus Sekolah

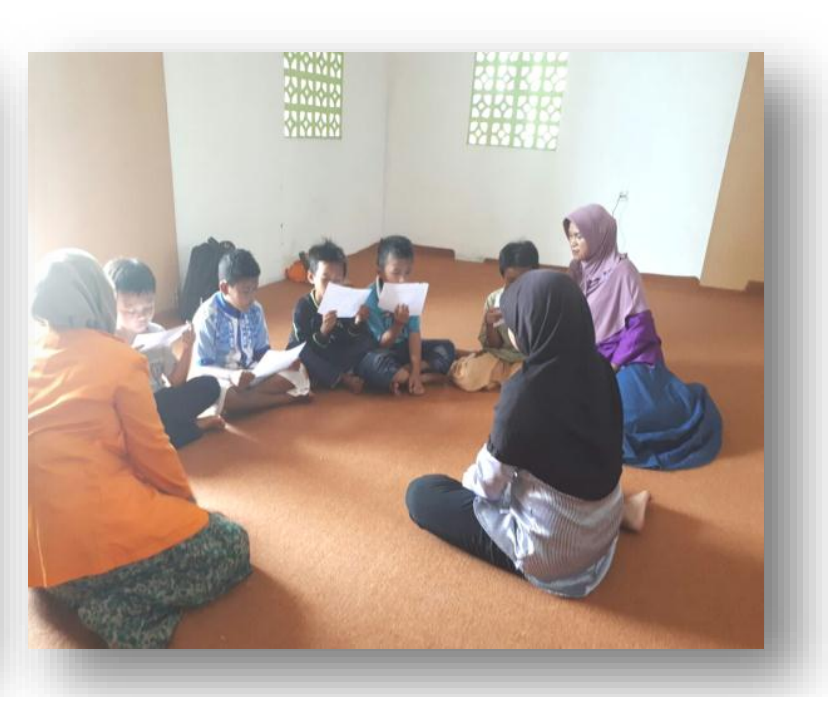

baca di Indonesia beserta dampak yang ditimbulkan apabila seseorang tidak dapat membaca dan malas untuk membaca. Pemberian materi budidaya literasi dapat dilihat pada gambar 1 .

Tidak hanya dengan pemaparan materi, selanjutnya para peserta dibentuk ke dalam beberapa kelompok baca yang terdiri dari berbagai kelas usia. Kemudian mereka diberikan penugasan membaca secara bergiliran untuk selanjuutnya saling berdiskusi dan memaparkan hasil pemahaman atau ilmu baru yang didapat di depan para peserta lain. Kegiatan pendampingan budidaya literasi pada masyarakat Kelurahan Gunung Bahagia dapat dilihat pada gambar 2. 

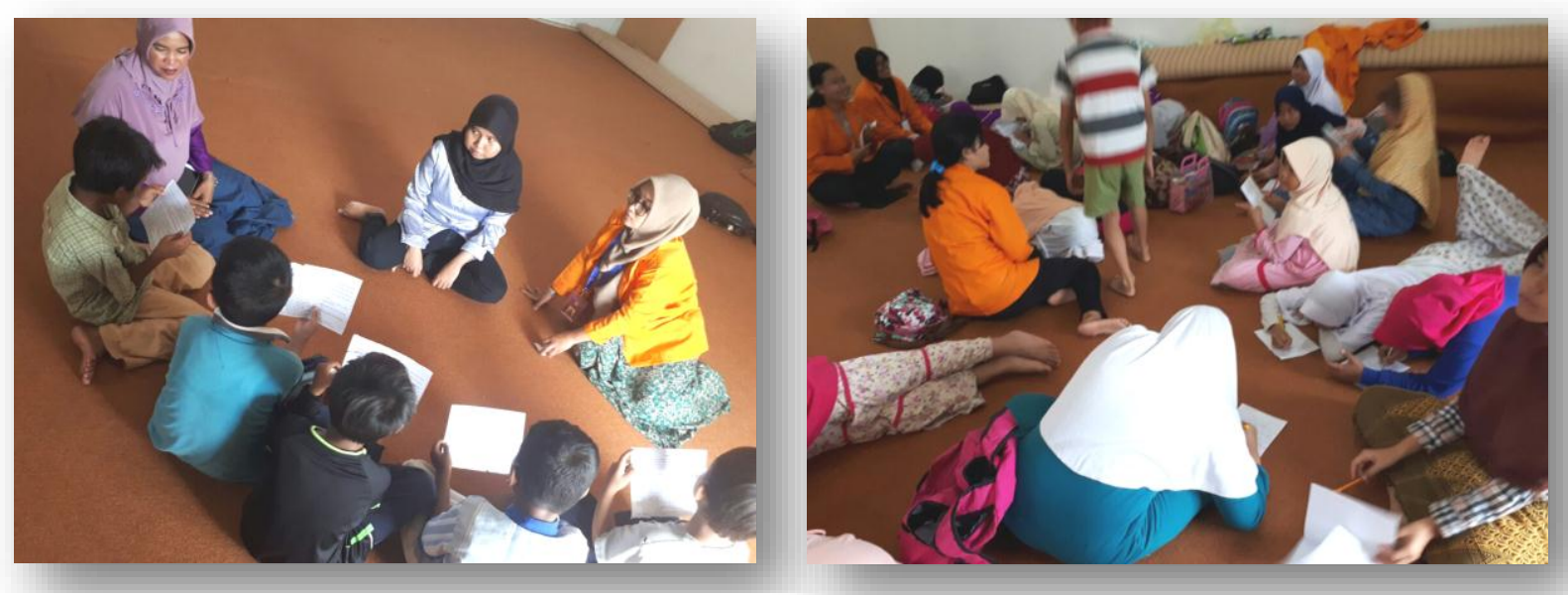

Gambar 3. Pendampingan Membaca Per-Kelompok pada Peserta SD, SMP, SMA

Pelaksanaan pendampingan membaca kepada para peserta ini dilaksanakan secara kontinu setiap akhir pekan untuk anak SD, SMP, dan SMA. Dan tiga kali tiap pekan untuk anak putus sekolah. Setiap pertemuan mereka diberikan bahan bacaan, bahan bacaan yang pengabdi berikan adalah dari sumber bacaan terpilih yang dapat menarik minat peserta untuk membaca. Usai itu, para peserta diminta untuk menulis atau berbicara untuk mengasah keterampilan bahasa pada dirinya agar lebih produktif setelah melatih kemampuan reseptif dari kegiatan membaca ataupun menyimak baik dari mendongeng maupun menonton video.

\begin{tabular}{|c|c|}
\hline \multicolumn{2}{|c|}{$\begin{array}{l}\text { Nama: Jasmin kartinl putri } \\
\text { Keas : VIll E } \\
\text { Sekolah I SMP }\end{array}$} \\
\hline \multicolumn{2}{|r|}{ (1) } \\
\hline$\square$ & Perlemaikan nama saya Jarmin kartinl purt \\
\hline & saya bansun pagi-pasi jam of. 15 mandi, lach \\
\hline & membersihkan remrar tidur pade pukul OQ.ll sara \\
\hline & menemani mama kepasar members sayur dan ikan \\
\hline & lalu pade puleal og. 45 saya beranglear sekolah buru \\
\hline & buru berangleat, sasalinya belum masukan. don de \\
\hline-1 & Selcolah saya de manahin oure marematica karna tidak \\
\hline & menserjakah PR Setelah itu Saya de hukam des derka \\
\hline$\square$ & dibawah untale manjutwen PR yang belum saxa \\
\hline$\square$ & ker Jakan dan pelajaran ke tag dan kecempar \\
\hline & korna Hdak adda gure bahase inggris jade sana \\
\hline$\checkmark$ & bermaln dengan tanan sara. Pada walctulu pulang secolat \\
\hline$\square$ & saya menemant teman de seleoloh, den saya pulang agale \\
\hline$\square$ & taat, sctelah sampal dr rumah yah, kena marah \\
\hline$\square$ & lagr sama mama saya. Selesai 1111 \\
\hline
\end{tabular}

Gambar 4. Hasil Karya Literasi 1 


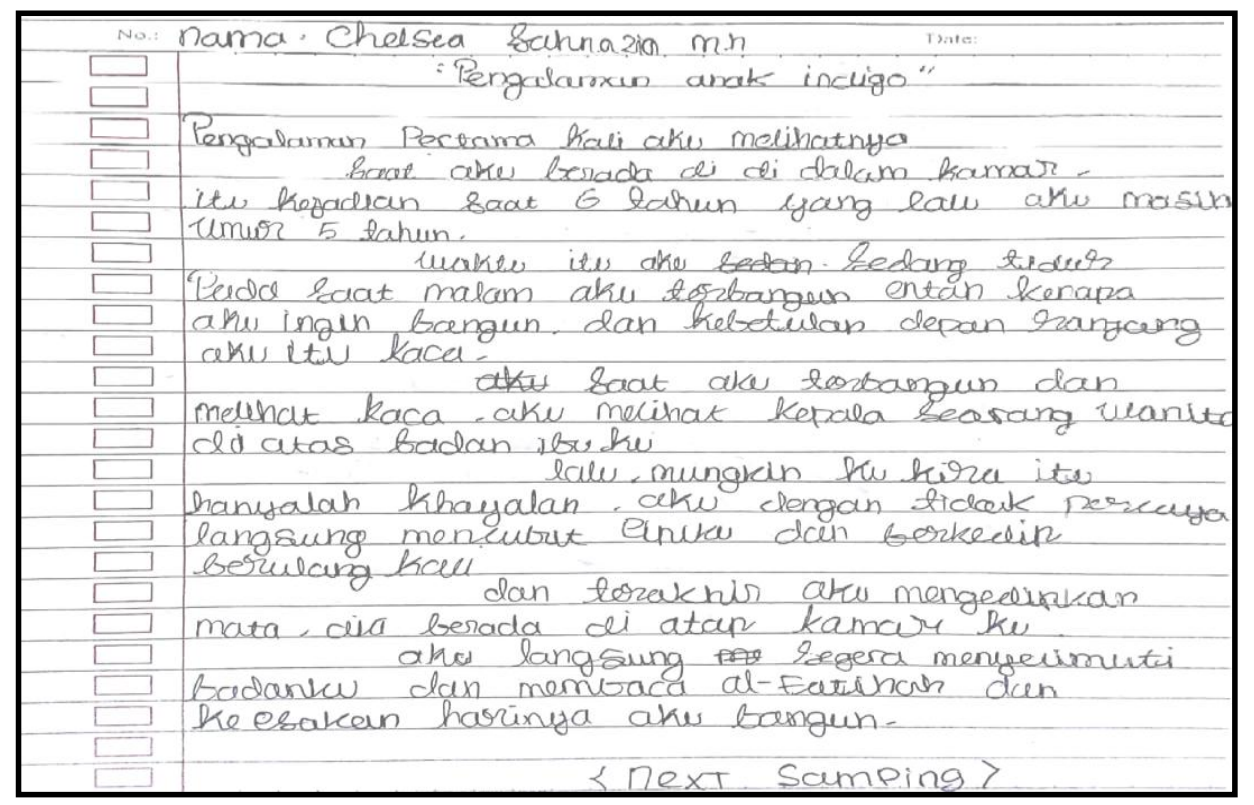

Gambar 5. Hasil Karya Literasi 1

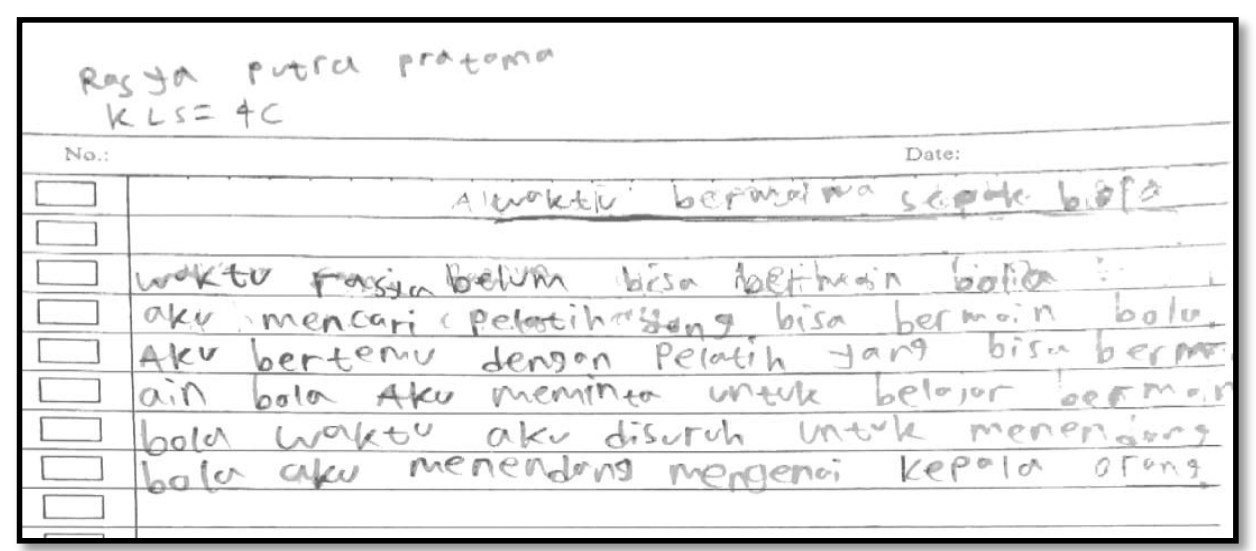

Gambar 6. Hasil Karya Literasi 3

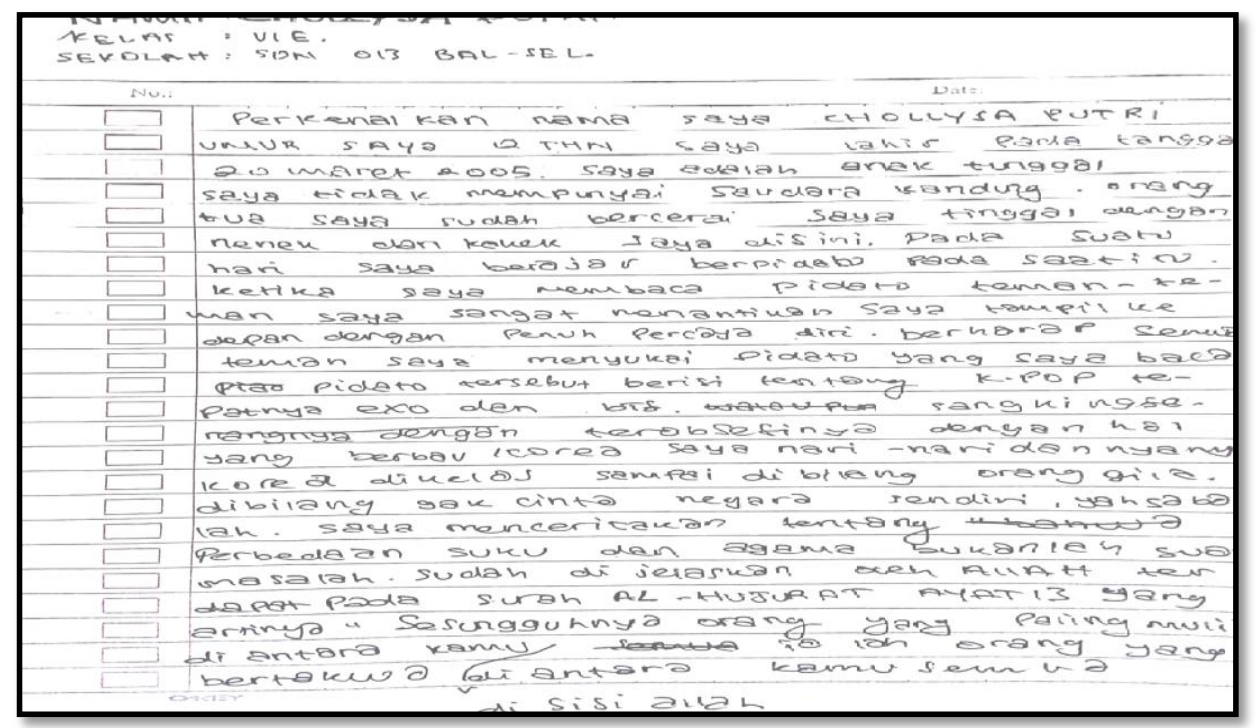

Gambar 7. Hasil Karya Literasi 4 
Hasil karya yang terlampir pada Gambar 4, 5, 6, dan 7 merupakan beberapa tulisan berbentuk narasi setelah berlatih membaca. Awalnya, mereka mengalami kesulitan namun dengan adanya penuangan pemahaman bahan bacaan melalui tulisan ini para peserta menjadi lebih kreatif. Dalam artian, para peserta dapat mengembangkan wawasan dan daya imajinasinya secara lebih luas. Selain itu, manfaat yang diperoleh setelah menulis ialah pengalaman yang akan dapat terus digunakan untuk masa mendatang. Dan juga, memudahkan peserta untuk memahami pelajaran di sekolah, karena dengan membaca dan menulis daya ingat mereka akan menjadi lebih baik.

Kemudian beberapa hasil karya dari budaya literasi peserta, pengabdi bukukan untuk dijadikan bahan bacaan berikutnya. Tujuannya yakni agar para peserta memperoleh hasil berupa kepuasan dan manfaat setelah mengikuti kegiatan budaya literasi. Secara signifikan, pengalaman belajar dan minat baca para peserta meningkat sejumlah $85 \%$ dari sebelumnya yang hanya $60 \%$. Hal ini dapat dilihat dari pemahaman yang diperoleh para peserta dan semangat para peserta dalam mengumpulkan bahan bacaan yang mereka gemari. Peran serta orang tua pun patut menjadi perhatian pengabdi. Oleh karena itu, pengabdi memberikan himbauan kepada para orang tua agar selepas kegiatan ini para peserta masih rutin untuk membaca.

\section{SIMPULAN DAN SARAN}

Kegiatan pengabdian kepada masyarakat yang dilaksanakan di Kelurahan Gunung Bahagia Kecamatan Balikpapan Selatan ini bertujuan untuk meningkatkan minat membaca dan kesadaran akan pentingnya membaca. Oleh sebab itu, dengan adanya kegiatan ini akan dapat meningkatkan minat membaca dan kesadaran akan pentingnya membaca pada masyarakat sekitar.

Berdasarkan beberapa dan kendala kekurangan tersebut di atas sebagai acuan dalam melaksanakan kegiatan yang akan datang. Berikut beberapa saran dan harapan panitia pengabdian kepada masyarakat.

1. Lebih antisipasi terhadap hal-hal yang mungkin terjadi di lapangan.

2. Hendaknya ada kritik dan saran demi perbaikan kegiatan yang akan datang.

3. Hendaknya ada kritik dan saran demi perbaikan kegiatan yang akan datang.

4. Hendaknya diusahakan mencari sponsor.
Demikian laporan kegiatan ini kami buat sebagai acuan dan pedoman dalam melaksanakan kegiatan periode yang akan datang

\section{DAFTAR PUSTAKA}

Hadianto. 2001. Minat Baca Orang Indonesia. Laman Republika, 26 Januari 2011. Diakses pada tanggal 01 Agustus 2018.

Presiden Republik Indonesia. Undang-undang Republik Indonesia Nomor 32 Tahun 2004. Tentang Pemerintah Daerah dan Otonomi Daerah. 